\title{
Low Dose Hyperbaric Bupivacaine and Dexmedetomidine as an Adjuvant in Spinal Anaesthesia, Caesarean Section: A Randomized Controlled Trial
}

Ahmed Ashraf Nasr ( $\nabla$ dr.ahmed.a.nasr@gmail.com )

Menoufia University Faculty of Medicine https://orcid.org/0000-0003-4755-8020

Safaa Mohamed Helal

Menoufia University Faculty of Medicine

Wesam Eldin Abdelrahman Soltan

Menoufia University Faculty of Medicine

Research article

Keywords: Caesarean-section, low-dose-bupivacaine, dexmedetomidine

Posted Date: June 12th, 2020

DOI: https://doi.org/10.21203/rs.3.rs-33452/v1

License: (c) (1) This work is licensed under a Creative Commons Attribution 4.0 International License.

Read Full License 


\section{Abstract \\ Background}

Alpha-2 agonist, e.g. dexmedetomidine, is a non-opioid adjuvant with a substantial role in extending the analgesic duration of the subarachnoid block. Here, we aim to test the efficacy of adding dexmedetomidine to hyperbaric bupivacaine in the caesarean delivery, targeting enhanced postoperative analgesia and more stable hemodynamics.

\section{Methods}

40 parturient women scheduled for elective caesarean section were enrolled and randomly allocated to two groups. Low Dose - Dexmedetomidine (LD- DEX) group $(n=20)$ received 7 mg hyperbaric bupivacaine plus $10 \mu$ g dexmedetomidine, control group $(n=20)$ received $12 \mathrm{mg}$ hyperbaric bupivacaine. Continuous normally distributed data were expressed as mean and standard deviation. Ordinal data and continuous data not fitting to the normal distribution curve were presented as medians (range) meanwhile categorical data were reported as percentage of the total number. Regarding the autonomic variables, we did a stratified analysis to compare the mean change of these variables every 3 minutes till 60 minutes through a two-sample t-test (Welch t-test). All statistical analyses were performed using $\mathrm{R}$ software version 3.4.4

\section{Results}

LD- DEX groups showed significant faster and prolonged sensory block ( $P$-value $<0.05)$, stable maternal hemodynamic maintained by less amount of IV fluids (P-value $<0.01$ ), lower doses of ephedrine (P-value $=0.02)$, no signs of foetal distress, and low incidence of postoperative maternal shivering. As well, 3 hours cut off pain was more significant in LD- DEX group (P-value $<0.01)$.

\section{Conclusion}

LD- DEX group provided an optimum intraoperative condition and postoperative analgesia with less maternal side effects and no neonatal risks, encouraging enhanced recovery and less hospital in-stay.

\section{Background}

Caesarean section (CS) is a life-saving surgical procedure, categorized as a major surgery that carries a direct twin maternal and perinatal threat with further consequences for later pregnancies.[1, 2] There is unavailable crude difference in superiority between general anaesthesia (GA) and regional anaesthesia (RA) as special anaesthetic plans in coping with CS where selection is commonly dependant on anaesthetist's preference and local policy.[3] RA is, however, gaining more preference amongst 
anaesthetist, with facts from the United Kingdom, for example, showing that RA is utilized in $94.9 \%$ and $86.7 \%$ of elective and emergent CS, respectively. [4] In RA, the key problems relate to insufficient blockade and induced haemodynamic instability. Different additives have been tested, including opioids, ketamine, midazolam, and a2-agonists, with the aim of improving block quality and providing better postoperative analgesia along with the maintenance of stable haemodynamic during surgery. Consequently, even in the postoperative environment, all need careful supervision and treatment. $[5,6]$

There was a growing interest in obstetric anaesthesia in the use of low-dose (LD) intrathecal hyperbaric bupivacaine "LD Scheme" ( $<8 \mathrm{mg}$ ) relative to the traditional dose ( $\geq 8 \mathrm{mg}$ ). This is based on the assumption that an increased dose of local anaesthetic (LA) IT injection will lead to a higher level of blockage and, subsequently, to profound sympathectomy-induced hypotension (SIH). Both doses were comparable to the values studied using dose-response curve modeling by logistic regression given an effective dose in 50 percent of the population (ED50) and an effective dose in 95 percent of the population (ED95) respectively. $[7,8]$

Alpha-2 agonists such as clonidine and dexmedetomidine (DEX) are non-opioid adjuvants with a significant role in extending the analgesic duration of the subarachnoid block, which reduces the need for postoperative opioid use.. [9-11] Several clinical trials have verified the analgesic advantages of neuraxial dexmedetomidine in non-obstetric settings. $[12,13]$ While intrathecal (IT) clonidine has been shown to be a useful analgesic supplement for spinal anaesthesia (SA) in patients undergoing CS. [14, 15] Animal studies showed a safe profile for intrathecal injection of dexmedetomidine and no risk for induced neurotoxicity. [16, 17]

Our research suggested that the use of LD-scheme with hyperbaric bupivacaine and dexmedetomidine as an adjuvant would provide optimum intraoperative surgical conditions, strong postoperative analgesia and more stable hemodynamics.

\section{Methods}

This was a prospective double-blind randomized controlled trial (RCT) including 40 parturient women scheduled for elective CS, it was retrospectively registered at clinicaltrial.gov (NCT03775655) also, it gained accreditation from the local ethical committee prior to starting the study and we are adherent to CONSORT statement. Participants were enrolled between September 2018 and January 2019 after obtaining written informed consent.

The study included full-term pregnant women aged 18-35 with singleton gestation and American Society of Anaesthesiologists (ASA) physical status classes I and II, excluding high risk pregnancies, patients with co-morbidities, and height more than $170 \mathrm{~cm}$.

\section{Study Intervention}


Patients were given either $7 \mathrm{mg}$ hyperbaric bupivacaine and $10 \mu \mathrm{g}$ dexmedetomidine (LD-DEX) or $12 \mathrm{mg}$ hyperbaric bupivacaine (Control group). All doses were diluted with saline to a total volume of $2.5 \mathrm{~cm}$ in an unlabelled syringe. The study medication was prepared with (A.H.Z) who was not involved in further perioperative care, data gathering or data analysis.

\section{Anaesthetic and Perioperative Management}

We standardized the anaesthetic technique for all participants. After an overnight fast, parturient was premedicated with intravenous (IV) ranitidine $50 \mathrm{mg}$, metoclopramide $10 \mathrm{mg}$ given 30 minutes prior to the scheduled time for CS. Patients was instructed on the use of the Visual Analog Scale (VAS): zero = no pain and $10=$ maximal unbearable pain.

Upon arrival to the operating room, Electrocardiogram (ECG), pulse oximetry $\left(\mathrm{SpO}_{2}\right)$ and non-invasive blood pressure (NIBP) was monitored. IV Lactated Ringer's solution of $500 \mathrm{ml}$ was started, lumbar puncture was performed in the sitting position at the $L_{3}-L_{4}$ level through a midline/ Para median approach using a 25G Quincke spinal needle preceded with local infiltration with $1 \mathrm{ml}$ of lidocaine $2 \%$ using $27 \mathrm{G}$ insulin syringe needle. In case of failed block (failure of sensory level to reach T10 level after 15 minutes), conversion to general anaesthesia was done. In cases of inadequate block (sensory level reached higher than T10 level, but traction pain was perceived intra-operatively), fentanyl was administered by IV in incremental doses of $50 \mu \mathrm{g}$ plus midazolam with maximum dose of $3 \mathrm{mg}$. With a persisted pain, conversion to general anaesthesia was done.

Hypotension, defined as a decrease of systolic blood pressure by more than $30 \%$ from baseline or a fall below $90 \mathrm{mmHg}$, will be treated with incremental IV doses of ephedrine $6 \mathrm{mg}$ and additional IV fluid as required. Bradycardia, defined as heart rate $<60$ beat per minute $(\mathrm{bpm})$, will be treated with IV atropine $0.5 \mathrm{mg}$. Postoperatively, patients received $30 \mathrm{mg}$ of IV ketorolac.

\section{Study Outcomes and data collection}

The primary outcome was haemodynamic stability and total doses of IV fluids and vasopressors, motor block density, the need of post-operative analgesia. Sensory level testing was, then, assessed by loss of pinprick sensation in each dermatomal level at mid-clavicular line every 2 min till the highest level was stabilized for four consecutive tests, every 10 minutes till the point of two segment regression of the block, and every 20 minutes till the recovery of $S_{1}$ dermatome. Motor block was, also, assessed using the modified Bromage scale [18]. The pain score was recorded initially every $1 \mathrm{~h}$ for $2 \mathrm{~h}$, then every $2 \mathrm{~h}$ for the next $8 \mathrm{~h}$ and then after every $4 \mathrm{~h}$ till $24 \mathrm{~h}$. When VAS score was above three, IV meperidine (Pethidine) $1 \mathrm{mg} / \mathrm{kg}$ was given as a rescue analgesic. Hemodynamic parameters (NIBP and heart rate (HR)) were recorded every three minutes during the whole operation. The total doses of fluids and vasopressors were recorded at the end of operation. The level of sedation was assessed intra and post-operatively using the modified Ramsay Sedation Score [19]. The incidence of desaturation during surgery or PACU stay was recorded. However, nasal prongs were provided (Oxygen $2 \mathrm{~L} / \mathrm{min}$ ) when arterial oxygen saturation decreases to $<92 \%$. 
The incidence of other adverse effects, such as nausea, vomiting, shivering, pruritus, and respiratory depression was recorded. The Apgar scores of the new-born was assessed at 1 and 5 min after birth. All data were collected blindly by the assistant nurses.

\section{Sample size calculation and statistical analysis}

Based on result of Kanazi et al [9], we calculated that 12 patients per group would provide $80 \%$ power to detect difference in the time to two segment regression with type I level of $5 \%$. However, to compensate for possible dropouts, additional $40 \%$ was added and the final sample size was 20 patients in each group.

Patient was randomly allocated to either groups LD-DEX group and control group, randomization done electronically.

All durations were calculated considering the time of spinal injection as time zero. Descriptive statistics were made for all variables. Continuous normally distributed data were expressed as mean and standard deviation (SD). Ordinal data and continuous data not fitting to the normal distribution curve were presented as medians (range) meanwhile categorical data were reported as percentage of the total number. Regarding the autonomic variables (SBP, DBP, HR), the 2 groups were compared on baseline characteristics to ensure that there was no difference between the compared groups prior to our clinical testing. We then did a stratified analysis to compare the mean change of these variables every 3 minutes till 60 minutes through a two-sample t-test (Welch t-test). All tests were two-sided with statistical significance below 0.05 . All statistical analyses were performed using $R$ software version 3.4.4 ( $R$ Foundation for Statistical Computing, Vienna, Austria). Our figures were generated using R package "ggplot2" [20].

\section{Results}

Two patients were excluded from the control group due to conversion to general anaesthesia, as shown in flow chart Fig. 1. Patients in the two groups didn't show statistical difference regarding baseline characteristics (P -value > 0.05). The mean height, and weight of LD- DEX group was $163.3(3.8) \mathrm{cm}, 70.2$ (1.5) kg versus $164.4(3.3) \mathrm{cm}, 68.9$ (2.7) kg for control group, respectively. Additionally, the preoperative vital signs of patients were comparable with no statistical significance. The mean HR was 102.7 (13.8) bpm versus 100.7 (17.4) bpm in LD -DEX group and control group respectively, while mean arterial pressure (MAP) was 90.2 (11.4) $\mathrm{mmHg}$ and 89.1 (13.5) $\mathrm{mmHg}$ in both groups respectively. However, the average duration of surgery in LD- DEX group was less than the control group (55.2 (13.3) min. and 65.2 $(10.6)$ min respectively, P-value $=0.02)($ Table 1$)$ 
Table 1

Demographic data and Surgical characteristics of the enrolled participants

\begin{tabular}{|llll|}
\hline & LD - DEX group & Control group & P - Value \\
\hline N (mean \pm SD) & 20 & 18 & \\
\hline Age (years) & $25.3(2)$ & $25.9(2)$ & 0.333 \\
\hline Height (cm) & $163.3(3.8)$ & $164.4(3.3)$ & 0.342 \\
\hline Weight (Kg) & $70.2(1.5)$ & $68.9(2.7)$ & 0.076 \\
\hline Gestational age (weeks) & $39(0.9)$ & $39(1)$ & 0.669 \\
\hline Duration of surgery (Min.) & $55.2(13.3)$ & $65.2(10.6)$ & 0.015 \\
\hline HR (bpm) & $102.7(13.8)$ & $100.7(17.4)$ & 0.698 \\
\hline SBP (mmHg) & $90.8(12.1)$ & $75(12.3)$ & 0.151 \\
\hline DBP (mmHg) & $128.3(15.1)$ & $120.7(11.2)$ & 0.088 \\
\hline MAP (mmHg) & $90.2(11.4)$ & $89.1(13.5)$ & 0.789 \\
\hline
\end{tabular}

\section{Sensory block and analgesia}

Control group demonstrated a shorter time to reach the peak sensory block level -fast onset- and shorter duration of S1 dermatome pain perception and a lower postoperative analgesic effect with about 3-hours cut off pain value - in which VAS scores $>3-(P<0.05$ in all except duration of $S 1$ dermatome pain perception $\mathrm{P}=0.06)$. (Table 2$)$ 
Table 2

Spinal block characteristics and analgesia

\begin{tabular}{|llll|}
\hline & LD - DEX group & Control group & P - Value \\
\hline N (\% or mean \pm SD) & 20 & 18 & \\
\hline Sensory block and analgesia & & & \\
\hline Duration to highest level (Min.) & $14.7(6.1)$ & $10(3.4)$ & 0.01 \\
\hline Duration of S1 (Min.) & $499(172.4)$ & $404.4(124.3)$ & 0.06 \\
\hline 3-hours cut off pain (hr.) & $6.3(2.1)$ & $3(1.8)$ & $<0.01$ \\
\hline Motor block & & & \\
\hline Motor block grade $=2$ & $20(100)$ & $22.6(16.1)$ & $<0.02$ \\
\hline Vuration till ambulation (Min.) & $206(60.9)$ & $421.8(122.8)$ & $<0.01$ \\
\hline Vasopressors and fluids & & & \\
\hline
\end{tabular}

\section{Motor block characteristics}

Regarding motor block, Control group showed denser block, 15 patients (83.3\%) reached grade 1 block while only 3 patients $(16.7 \%$ ) remained with grade 2 block unlike all participants of LD-DEX group (20 patients) that remined with grade 2 block which resulted in early ambulation with LD-DEX group after about 206 (60.9) $\min (P<0.01)$. (Table 2)

\section{Autonomic effects, fluids and vasopressors}

During sequential follow up of autonomic parameters, there were no significant difference between the two groups in the sixty minutes measurements. However, patients in LD- DEX group demonstrated significant increase in SBP at 12 minutes $(P=0.035)$, significant increase in DBP at 12 and 18 minutes ( $=0.039, P=0.011)$ Fig. 3. , and significant decrease in $H R$ at 36 and 45 minutes $(P=0.006, P=0.034)$.

(Fig. 2-4)

More doses of ephedrine 22.6 (16.1) mg and IV fluids 2361.1 (287.3) $\mathrm{ml}(\mathrm{P}<0.05)$ were used in control group just to maintain hemodynamic profile of patients close to their preoperative data and LD- DEX group. (Table 2)

\section{Side effects and foetal characteristics}


Control group showed higher incidence of shivering $(P<0.05)$ than LD- DEX group while both groups showed equal incidence of nausea and vomiting. Traction pain, particularly during exteriorization of uterus was higher but not statistically significant in LD- DEX group ( $P$-value $=0.13)$. All patients showed a sedation score $<2$ at every time point with no need for oxygen supplementation all over the operation. In both groups, new-born have no signs of foetal distress, evidenced by Apgar score at $1 \mathrm{~min}$. and $5 \mathrm{~min}(\mathrm{P}$ $>0.05$ ) (Table 3).

Table 3

Reported side effects and fetal outcomes in both

groups

\begin{tabular}{|llll|}
\hline & LD- DEX group & Control & P - Value \\
\hline N (\% or mean \pm SD) & 20 & 18 & \\
\hline Nausea & $4(20.0)$ & $4(22.2)$ & 1 \\
\hline Vomiting & $1(5.0)$ & $1(5.6)$ & 1 \\
\hline Traction pain & $6(30.0)$ & $1(5.6)$ & 0.13 \\
\hline Shivering & $1(5.0)$ & $8(44.4)$ & 0.01 \\
\hline Apgar 1 min & $8.7(0.5)$ & $8.7(0.5)$ & 0.64 \\
\hline Apgar 5 min & $9.4(0.5)$ & $9.3(0.5)$ & 0.44 \\
\hline Legends of figures & & \\
\hline
\end{tabular}

\section{Discussion}

Along the past time, researchers are addressing the optimal conditions of parturient female to provide an optimum intraoperative condition with stable hemodynamic, good postoperative analgesia and early ambulation with minimal maternal and foetal side effects targeting enhanced recovery after CS. According to our results, LD- DEX group showed better sensory block, longer postoperative analgesia, less dense motor block with earlier ambulation, stable maternal hemodynamic maintained by lower amounts fluids and ephedrine, and less shivering with no neonatal side effects.

Ginosar et.al., reported ED50 of hyperbaric bupivacaine ranges from $4.8 \mathrm{mg}$ to $9.8 \mathrm{mg}$ and the ED95 ranges from $8.8 \mathrm{mg}$ to $15 \mathrm{mg}$ [8]. Meanwhile we used, throughout our study hyperbaric bupivacaine at dose of $7 \mathrm{mg}$ and $10 \mu \mathrm{g}$ dexmedetomidine as LD-DEX group versus $12 \mathrm{mg}$ as control group. Dexmedetomidine proved to enhance sensory block and post-operative analgesic effect of IT hyperbaric bupivacaine $(P<0.05$ in all except duration of $S 1$ dermatome pain perception $P=0.06)$. that was supported by other reports in literature. [21-24] The mechanism of action of dexmedetomidine could be 
due to binding to pre-synaptic C-fibres and post-synaptic dorsal horn neurons which causes decreased release of $\mathrm{C}$-fibres neurotransmitters and hyperpolarization of post-synaptic dorsal horn neurons. $[25,26]$

Regarding motor block, our results showed a weak degree of block 2 degree according to modified Bromage score [18] which is suitable for that LD of hyperbaric bupivacaine and help early ambulation postoperative and regaining the muscle power which is reported to be $206(60.9) \mathrm{min}$. and came parallel to 331 (35) $\mathrm{min}$. that is reported by Shukla et.al., using $15 \mathrm{mg}$ hyperbaric bupivacaine and about 221.1 (1.37) min as reported by Fyneface- Ogan et.al., [27, 28]

That decreased dose resulted in more stable maternal hemodynamic profile and subsequently, less IV fluids and ephedrine than used for control group to be maintained, which came parallel to what is reported by Al-Mustafa and colleagues [29] and El-lakany [22]. Follow up of BP measurements, there was an initial increase in BP lasting for 12 minutes followed by hypotensive episodes with well response to IV fluids and ephedrine. However, that biphasic response had no effect on mean blood pressure which also approved by Kanazi et.al. [30] taking in consideration different populations of reported studies and different doses of hyperbaric bupivacaine that is used which was $12.5 \mathrm{mg}, 17.5 \mathrm{mg}$, respectively and $7 \mathrm{mg}$ in our study. That 12 minute- hypertensive episode would allow a good time for co-loading and delivery of the foetus decreasing episodes of foetal hypoperfusion due to decreased blood pressure.

As well, shivering in LD- DEX group showed a good profile with incidence of $5 \%$ which is much lower $(\mathrm{P}<$ 0.05) and came parallel to reports by Abdelhamid and El-lakany [22], Y. Sun et.al., [31] and K. Nasseri et.al., [32] Regarding nausea with or without vomiting there is no difference in incidence and is well corelated to episodes of hypotension and peritoneal traction parallel to outlined by Kang et.al.[33]

We encountered several limitations in this study. Firstly, intravenous fluid regimen was not standardized during the surgical procedure and was left up to judgement of the attending anaesthesiologist. However, that had no potential impact on our outcomes. The second limitation was the use of lower concentrations of LA. Nonetheless, the dose of LA and not the volume or concentration is the major determining factor in block height and motor block.[34] Finally, sample size was calculated based on two segment regression as the primary outcome which found to be statistically insignificant, hence, conclusions for others outcomes should be interpreted cautiously.

\section{Conclusion}

We conclude that LD- DEX scheme ( $10 \mu \mathrm{g}$ dexmedetomidine $+7 \mathrm{mg}$ hyperbaric bupivacaine) is an efficient option for intrathecal injection in patients scheduled for elective caesarean section as it provides better sensory block, more stable maternal hemodynamic with less vasopressors and fluids, good postoperative analgesia, early ambulation and less hospital in-stay.

List of abbreviations

\section{Abbreviations}




\begin{tabular}{|c|c|c|c|}
\hline ASA & American Society of Anesthesiologists & LD & low dose \\
\hline IT & Intrathecal & LA & local anesthetic \\
\hline IV & Intravenous & MAP & mean arterial pressure \\
\hline CS & caesarean section & NSAIDs & $\begin{array}{l}\text { Non-steroidal anti-inflammatory } \\
\text { drugs }\end{array}$ \\
\hline $\mathrm{SPO}_{2}$ & pulse oximetry & & \\
\hline CSF & cerebrospinal fluid & NIBP & non-invasive blood pressure \\
\hline $\mathrm{ED}_{50}$ & effective dose in $50 \%$ of population & PONV & postoperative nausea and vomiting \\
\hline DEX & Dexmedetomidine & DBP & diastolic blood pressure \\
\hline$E D_{90}$ & effective dose in $90 \%$ of population & RA & regional anesthesia \\
\hline $\mathrm{ED}_{95}$ & $\begin{array}{l}\text { effective analgesic dose for } 95 \% \text { of } \\
\text { patients }\end{array}$ & RSII & $\begin{array}{l}\text { Rapid sequence induction and } \\
\text { intubation }\end{array}$ \\
\hline ECG & Electrocardiogram & SA & spinal anesthesia \\
\hline GA & general anesthesia & SIH & $\begin{array}{l}\text { spinal anesthesia- induced } \\
\text { hypotension }\end{array}$ \\
\hline HR & heart rate & SBP & systolic blood pressure \\
\hline
\end{tabular}

\section{Declarations}

\section{Ethics approval and consent to participate}

An ethical approval was obtained from a local ethical committee with number of 050220181 and a photocopy of the approval is available upon request.

\section{Consent for publication}

Not applicable, we do not make it as we will not include any personal data throughout our publication.

\section{Availability of data and materials}

The datasets used and/or analysed during the current study are available from the corresponding author on reasonable request.

\section{Competing interest}

None of the authors have any conflicts of interest to declare. 


\section{Funding}

I would like to declare that I have not received any funding from any sources.

\section{Authors' contributions}

AAN: idea formulation, reviewing literature, study design, patient allocation, data analysis, writing the first draft, and approving the final draft; SMH: patient recruitment, data collection, writing first draft, and approving final draft; WAS: reviewing literature, patient recruitment, data collection, study design, critical revising for the first draft, and approving final draft. All authors have read and approved the manuscript.

\section{Acknowledgment}

None

\section{References}

1. Gregory KD, Jackson S, Korst L, Fridman M. Cesarean versus vaginal delivery: whose risks? Whose benefits? Am J Perinatol. 2012;29:7-18. doi:10.1055/s-0031-1285829.

2. Marshall NE, Fu R, Guise J-M. Impact of multiple cesarean deliveries on maternal morbidity: a systematic review. Am J Obstet Gynecol. 2011;205:262.e1-8. doi:10.1016/j.ajog.2011.06.035.

3. Afolabi BB, Lesi FE. Regional versus general anaesthesia for caesarean section. In: Afolabi BB, editor. Cochrane Database of Systematic Reviews. Chichester: John Wiley \& Sons, Ltd; 2012. doi:10.1002/14651858.CD004350.pub3.

4. Jenkins JG, Khan MM. Anaesthesia for Caesarean section: a survey in a UK region from 1992 to 2002. Anaesthesia. 2003;58:1114-8. doi:10.1046/j.1365-2044.2003.03446.x.

5. Stuart P. Novel additives to neuraxial blockade. South African J Anaesth Analg. 2011;17:86-9.

6. $10.5772 / 58851$

Goma HM, Flores-Carrillo JC, Whizar-Lugo VM. Spinal Additives in Subarachnoid Anaesthesia for Cesarean Section. In: Topics in Spinal Anaesthesia. InTech; 2014. doi:10.5772/58851.

7. Carvalho B, Durbin M, Drover DR, Cohen SE, Ginosar Y, Riley ET. The ED50 and ED95 of intrathecal isobaric bupivacaine with opioids for cesarean delivery. Anesthesiology. 2005;103:606-12. http://www.ncbi.nlm.nih.gov/pubmed/16129987.

8. Ginosar Y, Mirikatani E, Drover DR, Cohen SE, Riley ET. ED50 and ED95 of intrathecal hyperbaric bupivacaine coadministered with opioids for cesarean delivery. Anesthesiology. 2004;100:676-82. http://www.ncbi.nlm.nih.gov/pubmed/15108985.

9. Kanazi GE, Aouad MT, Jabbour-Khoury SI, Al Jazzar MD, Alameddine MM, Al-Yaman R, et al. Effect of low-dose dexmedetomidine or clonidine on the characteristics of bupivacaine spinal block. Acta 
Anaesthesiol Scand. 2006;50:222-7. doi:10.1111/j.1399-6576.2006.00919.x.

10. Gupta R, Bogra J, Verma R, Kohli M, Kushwaha JK, Kumar S. Dexmedetomidine as an intrathecal adjuvant for postoperative analgesia. Indian J Anaesth. 2011;55:347-51. doi:10.4103/00195049.84841.

11. Kirksey MA, Haskins SC, Cheng J, Liu SS. Local Anesthetic Peripheral Nerve Block Adjuvants for Prolongation of Analgesia: A Systematic Qualitative Review. PLoS One. 2015;10:e0137312. doi:10.1371/journal.pone.0137312.

12. Bajwa SJS, Singh A, Arora V, Kaur J, Parmar S. Comparative evaluation of dexmedetomidine and fentanyl for epidural analgesia in lower limb orthopedic surgeries. Saudi J Anaesth. 2011;5:365. doi:10.4103/1658-354X.87264.

13. Shukla D, Agarwal A, Tyagi C, Verma A, Pandey H. Comparative study of intrathecal dexmedetomidine with intrathecal magnesium sulfate used as adjuvants to bupivacaine. J Anaesthesiol Clin Pharmacol. 2011;27:495. doi:10.4103/0970-9185.86594.

14. Bajwa SJS, Bajwa SK, Kaur J, Singh A, Singh A, Parmar SS. Prevention of hypotension and prolongation of postoperative analgesia in emergency cesarean sections: A randomized study with intrathecal clonidine. Int J Crit IIIn Inj Sci. 2012;2:63-9. doi:10.4103/2229-5151.97269.

15. Lavand'homme PM, Roelants F, Waterloos H, Collet V, De Kock MF. An evaluation of the postoperative antihyperalgesic and analgesic effects of intrathecal clonidine administered during elective cesarean delivery. Anesth Analg. 2008;107:948-55. doi:10.1213/ane.0b013e31817f1595.

16. Brummett CM, Norat MA, Palmisano JM, Lydic R. Perineural administration of dexmedetomidine in combination with bupivacaine enhances sensory and motor blockade in sciatic nerve block without inducing neurotoxicity in rat. Anesthesiology. 2008;109:502-11. doi:10.1097/ALN.0b013e318182c26b.

17. Hou J, Xia Z, Xiao X, Wan X, Zhao B. Neurotoxicity of intrathecal injections of dexmedetomidine into the rat spinal dorsal horn. Neural Regen Res. 2012;7:1765-70. doi:10.3969/j.issn.16735374.2012.23.001.

18. Breen TW, Shapiro T, Glass B, Foster-Payne D, Oriol NE. Epidural anesthesia for labor in an ambulatory patient. Anesth Analg. 1993;77:919-24. http://www.ncbi.nlm.nih.gov/pubmed/8214727.

19. Ramsay MA, Savege TM, Simpson BR, Goodwin R. Controlled sedation with alphaxalonealphadolone. Br Med J. 1974;2:656-9. http://www.ncbi.nlm.nih.gov/pubmed/4835444.

20. 10.1007/978-3-319-24277-4

Wickham H. ggplot2. Cham: Springer International Publishing; 2016. doi:10.1007/978-3-319-242774.

21. Abdallah FW, Brull R. Facilitatory effects of perineural dexmedetomidine on neuraxial and peripheral nerve block: a systematic review and meta-analysis. Br J Anaesth. 2013;110:915-25. doi:10.1093/bja/aet066.

22. Mohamed H, El-lakany SAA. Intrathecal dexmedetomidine: Useful or not? J Anesth Clin Res. $2013 ; 04$. doi:10.4172/2155-6148.1000351. 
23. Kim JE, Kim NY, Lee HS, Kil HK. Effects of Intrathecal Dexmedetomidine on Low-Dose Bupivacaine Spinal Anesthesia in Elderly Patients Undergoing Transurethral Prostatectomy. Biol Pharm Bull. 2013;36:959-65. doi:10.1248/bpb.b12-01067.

24. Chattopadhyay I, Banerjee S, Jha A, Basu S. Effects of intrathecal dexmedetomidine as an additive to low-dose bupivacaine in patients undergoing transurethral resection of prostate. Indian J Anaesth. 2017;61:1002. doi:10.4103/ija.IJA_324_16.

25. Bajwa SJS, Gupta S, Kaur J, Singh A, Parmar S. Reduction in the incidence of shivering with perioperative dexmedetomidine: A randomized prospective study. J Anaesthesiol Clin Pharmacol. 2012;28:86-91. doi:10.4103/0970-9185.92452.

26. Eisenach JC, De Kock M, Klimscha W. alpha(2)-adrenergic agonists for regional anesthesia. A clinical review of clonidine (1984-1995). Anesthesiology. 1996;85:655-74.

http://www.ncbi.nlm.nih.gov/pubmed/8853097.

27. Fyneface-Ogan S, Gogo Job O, Enyindah CE. Comparative Effects of Single Shot Intrathecal Bupivacaine with Dexmedetomidine and Bupivacaine with Fentanyl on Labor Outcome. ISRN Anesthesiol. 2012;2012:1-6. doi:10.5402/2012/816984.

28. Shukla D, Verma A, Agarwal A, Pandey HD, Tyagi C. Comparative study of intrathecal dexmedetomidine with intrathecal magnesium sulfate used as adjuvants to bupivacaine. $J$ Anaesthesiol Clin Pharmacol. 2011;27:495-9. doi:10.4103/0970-9185.86594.

29. Al-Mustafa MM, Abu-Halaweh SA, Aloweidi AS, Murshidi MM, Ammari BA, Awwad ZM, et al. Effect of dexmedetomidine added to spinal bupivacaine for urological procedures. Saudi Med J. 2009;30:365-70. http://www.ncbi.nlm.nih.gov/pubmed/19271064.

30. Kanazi GE, Aouad MT, Jabbour-Khoury SI, Al Jazzar MD, Alameddine MM, Al-Yaman R, et al. Effect of low-dose dexmedetomidine or clonidine on the characteristics of bupivacaine spinal block. Acta Anaesthesiol Scand. 2006.

31. Sun Y, Xu Y, Wang GN. Comparative Evaluation of Intrathecal Bupivacaine Alone, Bupivacainefentanyl, and Bupivacaine-dexmedetomidine in Caesarean Section. Drug Res (Stuttg). 2014.

32. Nasseri K, Ghadami N, Nouri B. Effects of intrathecal dexmedetomidine on shivering after spinal anesthesia for cesarean section: A double-blind randomized clinical trial. Drug Des Devel Ther. 2017.

33. Kang YG, Abouleish E, Caritis S. Prophylactic intravenous ephedrine infusion during spinal anesthesia for cesarean section. Anesth Analg. 1982;61:839-42.

http://www.ncbi.nlm.nih.gov/pubmed/7125249.

34. Sheskey MC, Rocco AG, Bizzarri-Schmid M, Francis DM, Edstrom H, Covino BG. A dose-response study of bupivacaine for spinal anesthesia. Anesth Analg. 1983;62:931-5.

\section{Figures}




\section{Enrollment}
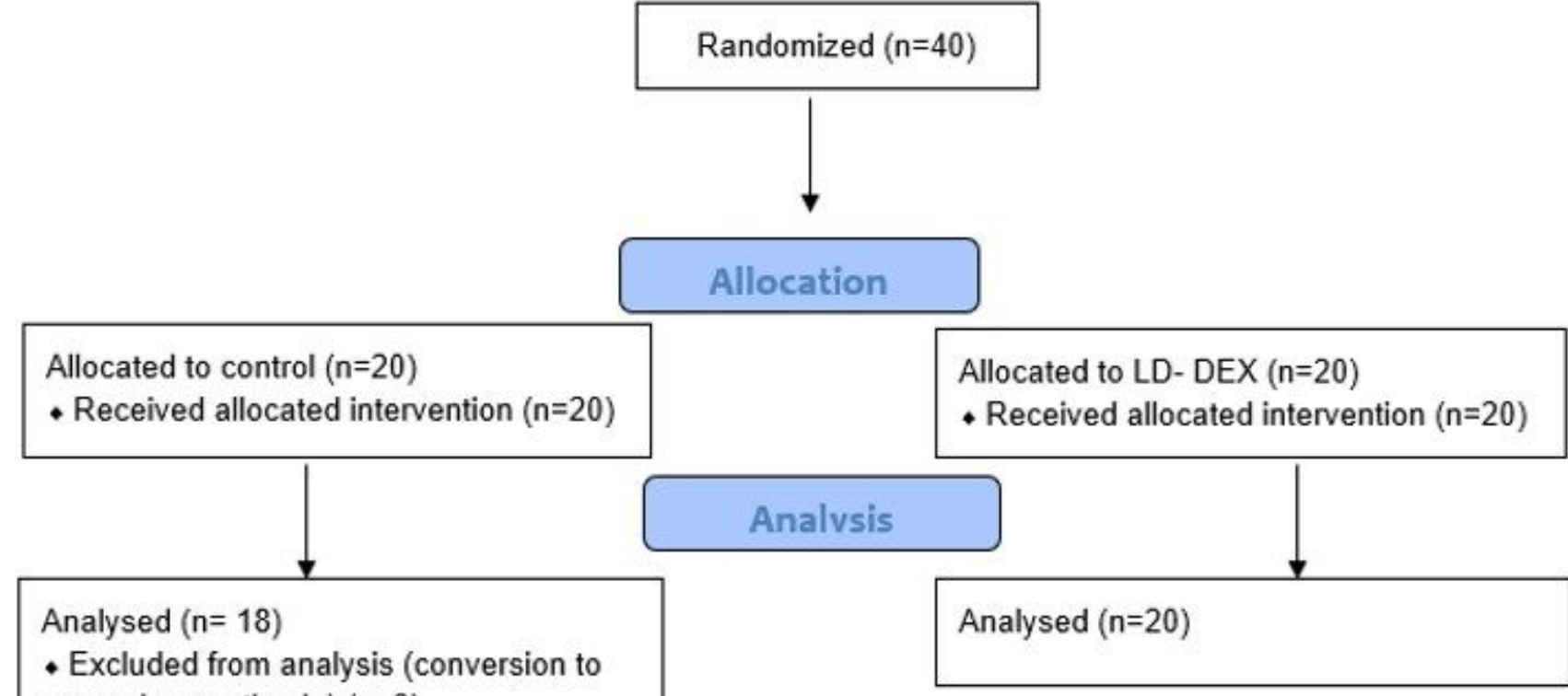

general anaesthesia) $(n=2)$

\section{Figure 1}

CONSORT flow diagram for enrollment 




Figure 2

The sequential changes in SBP measurements represented in mean with 95\% confidence interval. At 3 min. after SA induction mean SBP was 119.3 in LD- DEX group and 111.4 in control group. After 30 min. mean SBP was 109.2 in LD- DEX group and 106.8 in control group After 60 min. from induction the mean SBP was 104.2 in LD- DEX group and 112.7 in control group. 


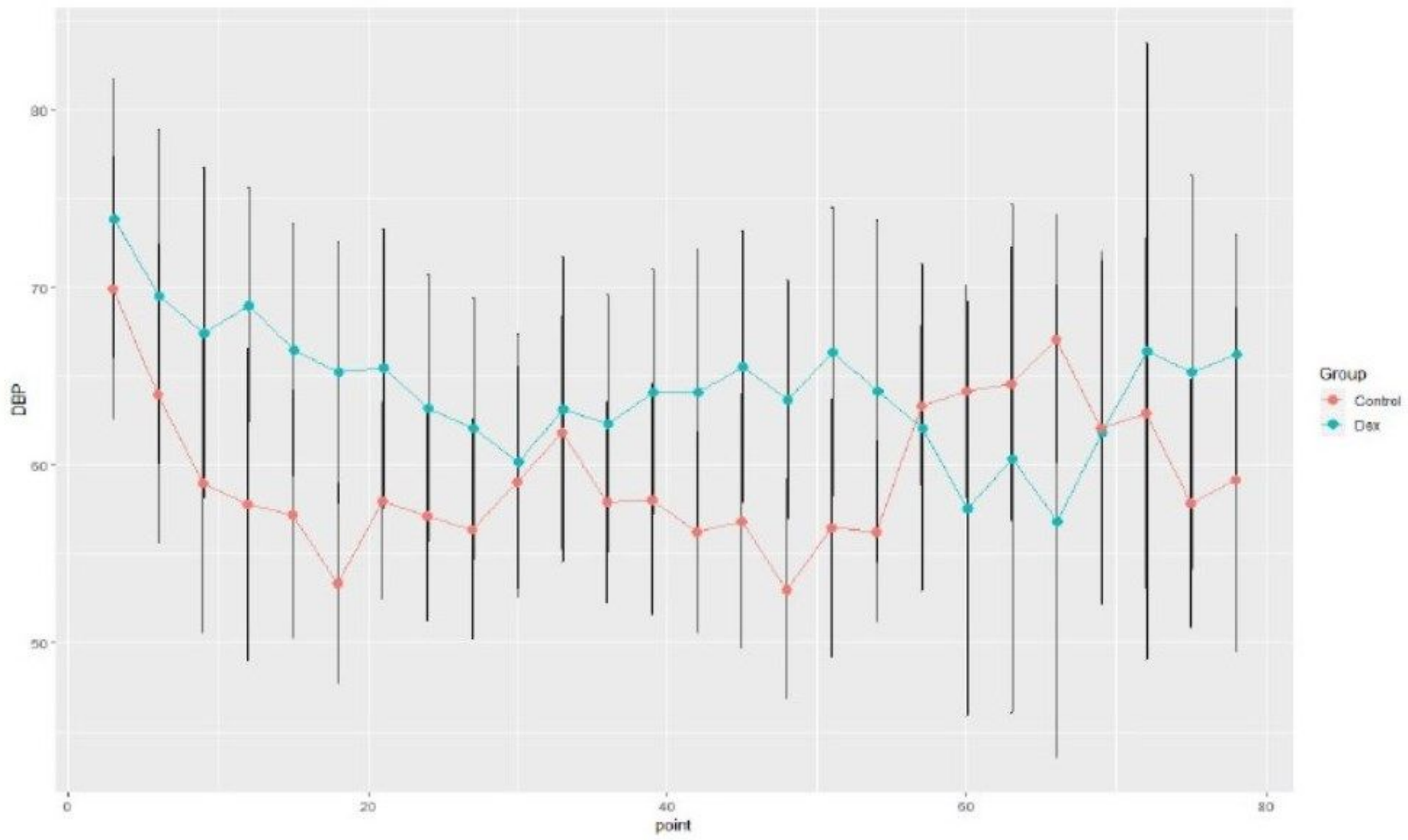

Figure 3

The sequential changes in DBP measurements represented in mean with 95\% confidence interval. At 3 min. after SA induction mean DBP was 73.8 in LD- DEX group and 69.9 in control group. After 30 min. mean DBP was 60.2 in LD- DEX group and 59.1 in control group After 60 min. from induction the mean DBP was 62.1 in LD- DEX group and 63.3 in control group. 




Figure 4

The sequential changes in HR measurements represented in mean with $95 \%$ confidence interval. At 3 min. after SA induction mean HR was 93.8 in LD- DEX group and 99.4 in control group. After 30 min. mean HR was 91.1 in LD- DEX group and 91.7 in control group After $60 \mathrm{~min}$. from induction the mean HR was 99.9 in LD- DEX group and 94.4 in control group.

\section{Supplementary Files}

This is a list of supplementary files associated with this preprint. Click to download.

- supplement8.doc 